\title{
HEALTH POLICY \\ The Roles of Cost and Quality Information in Medicare Advantage Plan Enrollment Decisions: an Observational Study
}

\author{
Rachel O. Reid, $M D, M S^{7}$, Partha Deb, $P h D^{2,3}$, Benjamin L. Howell, $P h D^{2}$, \\ Patrick H. Conway, MD, MSc ${ }^{2,4}$, and William H. Shrank, MD, MSHS ${ }^{1,2}$ \\ 'Department of Medicine, Brigham \& Women's Hospital, Boston, MA, USA; ${ }^{2}$ Centers for Medicare \& Medicaid Services, Center for Medicare \& \\ Medicaid Innovation, Baltimore, MD, USA; ${ }^{3}$ Department of Economics, Hunter College, New York, NY, USA; ${ }^{4}$ Cincinnati Children's Hospital Medical \\ Center, Cincinnati, $\mathrm{OH}$, USA.
}

BACKGROUND: To facilitate informed decision-making in the Medicare Advantage marketplace, the Centers for Medicare \& Medicaid Services publishes plan information on the Medicare Plan Finder website, including costs, benefits, and star ratings reflecting quality. Little is known about how beneficiaries weigh costs versus quality in enrollment decisions.

OBJECTIVE: We aimed to assess associations between publicly reported Medicare Advantage plan attributes (i.e., costs, quality, and benefits) and brand market share and beneficiaries' enrollment decisions.

DESIGN, SETTING, PARTICIPANTS: We performed a nationwide, beneficiary-level cross-sectional analysis of 847,069 beneficiaries enrolling in Medicare Advantage for the first time in 2011.

MAIN MEASURES: Matching beneficiaries with their plan choice sets, we used conditional logistic regression to estimate associations between plan attributes and enrollment to assess the proportion of enrollment variation explained by plan attributes and willingness to pay for quality.

KEY RESULTS: Relative to the total variation explained by the model, the variation in plan choice explained by premiums (25.7\%) and out-of-pocket costs (11.6\%) together explained nearly three times as much as quality ratings (13.6\%), but brand market share explained the most variation (35.3\%). Further, while beneficiaries were willing to pay more in total annual combined premiums and out-of-pocket costs for higher-rated plans (from \$4,154.93 for 2.5-star plans to \$5,698.66 for 5star plans), increases in willingness to pay diminished at higher ratings, from \$549.27 (95\%CI: \$541.10, \$557.44) for a rating increase from 2.5 to 3 stars to $\$ 68.22$ (95\%CI: $\$ 61.44, \$ 75.01)$ for an increase from 4.5 to 5 stars. Willingness to pay varied among subgroups: beneficiaries aged 64-65 years were more willing to pay for higherrated plans, while black and rural beneficiaries were less willing to pay for higher-rated plans.

CONCLUSIONS: While beneficiaries prefer higher-quality and lower-cost Medicare Advantage plans, marginal utility for quality diminishes at higher star ratings, and their

Electronic supplementary material The online version of this article (doi:10.1007/s11606-015-3467-3) contains supplementary material, which is available to authorized users.

Received December 29, 2014

Revised April 10, 2015

Accepted June 29, 2015

Published online August 18, 2015 decisions are strongly associated with plans' brand market share.

KEY WORDS: medicare advantage; insurance market; consumerism; quality reporting.

J Gen Intern Med 31(2):234-41

DOI: $10.1007 / \mathrm{s} 11606-015-3467-3$

(C) US Government 2015

\section{INTRODUCTION}

Medicare Advantage, which encompasses more than onequarter of Medicare beneficiaries and attracts an increasing share of new beneficiaries, ${ }^{1,2}$ relies on informed consumer cost-benefit decisions for its success as a market-based insurance model. The Centers for Medicare \& Medicaid Services (CMS) publishes the Medicare Plan Finder website to provide beneficiaries with information about plan benefits, premiums, out-of-pocket costs, and star ratings reflecting quality to enable plan comparisons. ${ }^{3}$ Assigned on a 1-to-5 star scale, the star ratings incorporate more than 50 measures across several dimensions of quality: process-based quality via Healthcare Effectiveness Data and Information Set (HEDIS) measures, satisfaction via the Consumer Assessment of Healthcare Providers and Systems (CAHPS) surveys, health outcomes via the Health Outcomes Survey, and administrative quality via customer service, complaints and appeals. ${ }^{4}$ The star ratings have garnered attention from insurers and policymakers, owing to Affordable Care Act provisions and CMS policies providing bonuses for higher-rated plans via increased rebate percentages and year-long open enrollment periods for 5-star plans as of 2012.

Yet, reports suggest that beneficiaries' use of the Plan Finder website and star ratings may be limited, due to challenges in accessing and interpreting the information there. ${ }^{5,6}$ Absent actionable plan information, choices may be informed by brand recognition, word of mouth, or other sources. ${ }^{7-9}$ When information is available, interpreting numerous complex options is challenging; ${ }^{10-15}$ beneficiaries may not be equipped to weigh the worth of attributes, including quality.

Public reporting of plan benefits, costs, and quality in this large national program provides a unique opportunity to assess plan preferences though actual enrollments. Studies in the 
commercial market demonstrate associations between preferences and plans' costs, benefits, and quality, ${ }^{7,16}$ and prior work demonstrates associations between Medicare Advantage star ratings and enrollment. ${ }^{17}$ However, the relative importance of cost and quality in Medicare Advantage choices is unknown.

In this study, we assess variation in Medicare Advantage enrollment decisions attributable to cost, quality, and market share and willingness to pay for quality.

\section{METHODS}

\section{Study Design}

We performed a beneficiary-level, cross-sectional analysis of Medicare Advantage and Prescription Drug (MAPD) plan choices for beneficiaries enrolling in Medicare Advantage for the first time in 2011. This was the first year of the combined overall star rating for MAPD plans incorporating both health and drug plan quality, and it preceded CMS policies beginning in 2012 that paid plans bonuses based on star ratings and provided year-long open enrollment for 5-star plans, which could confound associations between star ratings and enrollment. We focused on new enrollees to eliminate the influence of prior Medicare Advantage exposure. Employing a discrete choice approach, we assessed the proportion of enrollment variation explained by plan attributes and willingness to pay for quality.

Matching beneficiaries with their choice set of plans based on their county and capitalizing upon variation in plan attributes within and across choice sets, our design accounts for the Medicare Advantage market's structure. Sponsoring organizations (e.g., Aetna, Humana) offer CMS contracts for specific coverage types (e.g., HMO, PPO) and geographic service areas varying from a single county to many counties or states. A contract includes one or more plans of differing cost-sharing and benefits. Beneficiaries in a given county select one plan from a common choice set containing plans from multiple sponsoring organizations and contracts of varying geographic breadth and overlap. Because star ratings are assigned at the contract-level, a single rating applies to all plans therein, across the entire service area. In 2011, three MAPD contracts received 5 stars and some contracts were unrated because they were too new or small to provide the requisite data.

\section{Data}

Data was derived from CMS's Integrated Data Repository (enrollment and demographic data), ${ }^{18}$ CMS's Health Plan Management System (premiums, benefits, out-of-pocket costs, and service areas), ${ }^{19}$ and public files (star ratings). ${ }^{20}$

\section{Inclusion Criteria}

We included all 2011 non-employer-sponsored MAPD enrollments for beneficiaries without prior Medicare Advantage enrollments with a United States address corresponding to a choice set with two or more MAPD contracts. We included only MAPD plans, because these represent the vast majority of Medicare Advantage enrollments, as opposed to plans without prescription coverage. Because costs would differ, we excluded beneficiaries deemed eligible for the low-income subsidy $(N=105,283 ; 11 \%)$. To ensure accurate matching of beneficiaries with choice sets, we excluded beneficiaries with addresses that could not be definitively mapped to one county, out-of-service-area enrollment approvals, or enrolled plans whose service area excluded their address. To ensure a common choice set in each market, we excluded Special Needs, PACE, and employer plans. We excluded cost plans because their structure and coverage differ from Medicare Advantage plans, many had limitations on new enrollment, and none received overall star ratings in 2011 .

\section{Beneficiary-Level and Plan- Level Covariates}

We accounted for beneficiary age, gender, race/ethnicity ${ }^{21}$ and urban versus rural residence.

We accounted for plan attributes from the Plan Finder website and the local market contributing to choices: ${ }^{16,22,23}$ costs, quality, benefits, and market share. Costs were represented as shown on the Plan Finder by health and drug plan premiums (i.e., Part B, C, and D Premiums, less any rebates) and average estimated combined Part $\mathrm{C}$ and D out-of-pocket costs. Quality was represented via the overall combined Part C and D star rating. Benefits were represented via categorical variables for coverage-type (HMO, HMO-POS, Private Feefor-Service, Local PPO, or Regional PPO); maximum copayments or coinsurance for in-network primary care, specialist, and outpatient visits; Part C and D deductibles; and dental, vision, hearing, and prescription gap coverage. Sponsoring organization market share was represented via the percentage of Medicare Advantage enrollments (excluding PACE and employer plans) in December 2010 in each county for plans of a given sponsoring organization (i.e., the recognizable brand of a Medicare Advantage plan). Because a sponsoring organization may have more than one contract and plan in a service area, star ratings, premiums, and benefits may vary for a given sponsoring organization within a market. Analysis of plans attributes' correlation was not concerning for multicollinearity (Appendix).

\section{Regression Analyses}

We used conditional logistic regression to assess associations between plan attributes and enrollment. Our data included all possible pairings of each beneficiary and each plan available in their choice set, from which each beneficiary enrolled in exactly one plan. Our outcome variable was 1 for the plan chosen and 0 for all others in choice set. Because willingness to pay for an increase in star rating may vary at different ratinglevels, our model included the star rating itself, its quadratic transform, and an unrated plan indicator.

The conditional logit model estimates preferences based on the plans available in each beneficiary's actual choice set, 
accounting for variation in choices-set size and in the attributes of plans therein. The model's likelihood function is estimated on the basis of differences in attributes between pairwise sets of plans in each beneficiary's choice set; that is, a beneficiary's choice between plans only contributes to parameter estimates for a given plan attribute to the extent that the attribute varies between those plans. For example, if two plans in a choice set had the same contract and star rating, then a beneficiary's choice between the two does not contribute to estimates for star ratings, but does contribute for other attributes (i.e., costs, benefits) on which the plans differ. Further, those plans may ultimately contribute to estimates for star ratings to the extent that ratings of other plans in the choice set differ.

\section{Proportion of Variation Explained}

To estimate the fraction of the overall variation in enrollment decisions explained by all the plan attributes in our model, we calculated a pseudo- $\mathrm{R}^{2}$. To assess plan attributes' individual contributions to that explained variation in enrollment, we used the model parameter estimates to calculate the percentage of variance explained by covariate categories (premiums, out-ofpocket costs, quality, market share, and all other benefits in the model) relative to the cumulative variance explained by all the covariates in the model.

\section{Willingness to Pay}

We assessed marginal willingness to pay for quality - how much a beneficiary would pay for an increase in star rating to the next rating level — using the results of our conditional logit model (i.e., the ratio between the derivative of the choice probability with respect to star rating and the derivative of the choice probability with respect to cost). We assessed cumulative willingness to pay for a plan at each star ratinglevel by sequentially adding marginal willingness to pay for each increase in rating to the willingness to pay for an unrated plan. We used the total annual combined premiums and out-ofpocket costs to estimate willingness to pay via a single value encompassing both premiums and benefit generosity.

To estimate differential willingness to pay by beneficiary characteristics, we interacted beneficiary attributes (age, sex, race/ethnicity, rural/urban residence) with quality and cost in separate models. Because the conditional logit model estimates preferences for plan attributes based on variations within each beneficiary's actual choice set, the willingness to pay estimated for each subgroup reflects the actual choices faced by that subgroup, and does not assume even distribution of plan attributes across subgroups.

\section{RESULTS}

\section{Beneficiaries and Plans Included}

After inclusion criteria, 847,069 enrollees comprised the study population. Choice sets varied in size and content, on average including 16.5 plans, of which 13.1 received a star rating and 2.1 were rated 4 stars or higher (Table 1). While some plans in these choice sets shared a common contract, and consequently a common star rating, more than $90 \%$ of beneficiaries' choice sets contained more than half as many contracts as plans and nearly $20 \%$ contained more than three-quarters as many contracts as plans.

Plans with higher star ratings, lower premiums, mid-range out-of-pocket costs, no drug deductible, and PPO coveragetypes were more represented among enrolled plans than among all plans available across choice sets (Table 2).

\section{Enrollment Decision Variation}

Our model accounts for $18.7 \%$ of the overall variation in enrollment decisions, as assessed via a Psuedo- $\mathrm{R}^{2}$. Relative to the variation in enrollment decisions explained by our model, a plan's sponsoring organization market share accounted for the largest fraction (35.3\%). Cost-related variables accounted for the next largest fractions (health and drug plan premiums $25.7 \%$ and average estimated out-of-pocket costs $11.6 \%$ ) and star ratings for $13.6 \%$ (Fig. 1).

\section{Willingness to Pay for Quality}

Beneficiaries were willing to pay more for higher-rated plans. Mean willingness to pay in total annual combined premiums and out-of-pocket costs varied from $\$ 4,154.93$ for 2.5-star plans to $\$ 5,698.66$ for 5-star plans (Table 3). Increases in willingness to pay diminished at higher ratings; the marginal

Table 1. Characteristics of First-Time Medicare Advantage Enrollees

\begin{tabular}{|c|c|c|}
\hline Characteristic & $n^{a}$ & (\%) \\
\hline Total & 847,069 & \\
\hline \multicolumn{3}{|l|}{ Age } \\
\hline Less than $64 \mathrm{yr}$ & 145,612 & $(17.2 \%)$ \\
\hline $64-65 \mathrm{yr}$ & 361,914 & $(42.7 \%)$ \\
\hline $66-70 \mathrm{yr}$ & 188,879 & $(22.3 \%)$ \\
\hline $71 \mathrm{yr}$ or greater & 150,664 & $(17.8 \%)$ \\
\hline \multicolumn{3}{|l|}{ Sex } \\
\hline Female & 455,731 & $(53.8 \%)$ \\
\hline Male & 391,338 & $(46.2 \%)$ \\
\hline \multicolumn{3}{|l|}{ Race/Ethnicity ${ }^{b}$} \\
\hline White & 646,430 & $(76.3 \%)$ \\
\hline Black & 77,262 & $(9.1 \%)$ \\
\hline Hispanic & 68,769 & $(8.1 \%)$ \\
\hline Other & 54,608 & $(6.5 \%)$ \\
\hline \multicolumn{3}{|c|}{ Urban vs. rural residence } \\
\hline Rural & 144,376 & $(17.0 \%)$ \\
\hline Urban & 702,693 & $(83.0 \%)$ \\
\hline \multicolumn{3}{|l|}{ Region } \\
\hline Northeast & 153,005 & $(18.1 \%)$ \\
\hline South & 312,829 & $(36.9 \%)$ \\
\hline Midwest & 168,530 & $(19.9 \%)$ \\
\hline West & 212,705 & $(25.1 \%)$ \\
\hline \multicolumn{3}{|c|}{ No. of plans in choice set, mean (range) } \\
\hline All plans & 16.5 & $(2-48)$ \\
\hline Rated plans & 13.1 & $(1-42)$ \\
\hline Rated $4+$ stars & 2.1 & $(0-15)$ \\
\hline
\end{tabular}


Table 2. Characteristics of Plans Available Across Choice Sets and Actual Enrolled Plans

\begin{tabular}{|c|c|c|c|c|}
\hline \multirow[t]{2}{*}{ Characteristic } & \multicolumn{4}{|c|}{ no. of plans (\%) } \\
\hline & \multicolumn{2}{|c|}{$\begin{array}{l}\text { Characteristics of all plans } \\
\text { available across all } \\
\text { beneficiaries' choice sets } \\
\text { (each beneficiary counted } \\
\text { once for each plan in their } \\
\text { choice set) }\end{array}$} & \multicolumn{2}{|c|}{$\begin{array}{l}\text { Characteristics of plans in } \\
\text { which beneficiaries }_{\text {enrolled }^{\mathrm{a}} \text { (each beneficiary }} \text { counted only once, for } \\
\text { their enrolled plan) }\end{array}$} \\
\hline Total & $13,936,095$ & & 847,069 & \\
\hline \multicolumn{5}{|l|}{ Star rating } \\
\hline Unrated & $2,814,627$ & $(20.2 \%)$ & 86,047 & $(10.2 \%)$ \\
\hline 2.5 & $1,989,923$ & $(14.3 \%)$ & 64,443 & $(7.6 \%)$ \\
\hline 3 & $4,737,529$ & $(34.0 \%)$ & 342,533 & $(40.4 \%)$ \\
\hline 3.5 & $2,657,170$ & $(19.1 \%)$ & 180,117 & $(21.3 \%)$ \\
\hline 4 & 823,350 & $(5.9 \%)$ & 73,994 & $(8.7 \%)$ \\
\hline 4.5 & 855,655 & $(6.1 \%)$ & 92,891 & $(11.0 \%)$ \\
\hline 5 & 57,841 & $(0.4 \%)$ & 7,044 & $(0.8 \%)$ \\
\hline \multicolumn{5}{|l|}{ Monthly Part $\mathrm{C}$ premium ${ }^{\mathrm{b}}$} \\
\hline No premium & $7,085,687$ & $(50.8 \%)$ & 531,293 & $(62.7 \%)$ \\
\hline$\$ 0.01-\$ 12.70$ & 757,454 & $(5.4 \%)$ & 64,649 & $(7.6 \%)$ \\
\hline$\$ 12.71-\$ 51.00$ & $3,160,122$ & $(22.7 \%)$ & 143,128 & $(16.9 \%)$ \\
\hline$>\$ 51.00$ & $2,932,832$ & $(21.0 \%)$ & 107,999 & $(12.7 \%)$ \\
\hline \multicolumn{5}{|l|}{ Monthly Part D premium ${ }^{\mathrm{c}}$} \\
\hline No premium & $6,972,633$ & $(50.0 \%)$ & 549,522 & $(64.9 \%)$ \\
\hline$\$ 0.01-\$ 14.30$ & 729,909 & $(5.2 \%)$ & 40,331 & $(4.8 \%)$ \\
\hline$\$ 14.31-\$ 29.70$ & $3,022,803$ & $(21.7 \%)$ & 137,150 & $(16.2 \%)$ \\
\hline$>\$ 29.70$ & $3,210,750$ & $(23.0 \%)$ & 120,066 & $(14.2 \%)$ \\
\hline \multicolumn{5}{|l|}{ Monthly average estimated health and drug plan out-of-pocket costs } \\
\hline$\leq \$ 179.46$ & $4,109,951$ & $(29.5 \%)$ & 182,185 & $(21.5 \%)$ \\
\hline$\$ 179.47-\$ 209.30$ & $3,219,990$ & $(23.1 \%)$ & 237,450 & $(28.0 \%)$ \\
\hline$\$ 209.31-\$ 230.14$ & $3,172,574$ & $(22.8 \%)$ & 276,644 & $(32.7 \%)$ \\
\hline$>\$ 230.14$ & $3,433,580$ & $(24.6 \%)$ & 150,790 & $(17.8 \%)$ \\
\hline \multicolumn{5}{|l|}{ Health plan deductible } \\
\hline No deductible & $13,179,047$ & $(94.6 \%)$ & 799,006 & $(94.3 \%)$ \\
\hline Any deductible & 757,048 & $(5.4 \%)$ & 48,063 & $(5.7 \%)$ \\
\hline \multicolumn{5}{|l|}{ Drug plan deductible } \\
\hline No deductible & $11,879,003$ & $(85.2 \%)$ & 796,893 & $(94.1 \%)$ \\
\hline Any deductible & $2,057,092$ & $(14.8 \%)$ & 50,176 & $(5.9 \%)$ \\
\hline \multicolumn{5}{|l|}{ Coverage type } \\
\hline Health Maintenance Organization (HMO) & $6,420,724$ & $(46.1 \%)$ & 348,330 & $(41.1 \%)$ \\
\hline Health Maintenance Organization Point-of-Service (HMO-POS) & $1,641,156$ & $(11.8 \%)$ & 133,485 & $(15.8 \%)$ \\
\hline Local Preferred Provider Organization (PPO) & $2,775,306$ & $(19.9 \%)$ & 191,869 & $(22.7 \%)$ \\
\hline Regional Preferred Provider Organization (PPO) & $1,517,305$ & $(10.9 \%)$ & 130,920 & $(15.5 \%)$ \\
\hline Private Fee-For-Service (PFFS) & $1,581,604$ & $(11.3 \%)$ & 42,465 & $(5.0 \%)$ \\
\hline
\end{tabular}

${ }^{a}$ Enrollment data pulled from CMS Integrated Data Repository (IDR) on 19 April 2012

${ }^{b}$ Part $C$ Premium, less Part $B$ rebate

${ }^{c}$ Total Premium, net rebate

increase in willingness to pay for an additional 0.5 stars varied from $\$ 549.27$ (95\%CI $\$ 541.10$ to $\$ 557.44$ ) to go from a 2.5 to a 3-star plan to $\$ 68.22$ (95\% CI $\$ 61.44$ to $\$ 75.01)$ to go from a 4.5 to a 5 -star plan. Compared to other ages, beneficiaries aged 64-65 years were more willing to pay for higher-rated plans (Fig. 2, Appendix). Black and rural beneficiaries were less willing to pay for higher-rated plans.

\section{Sensitivity Analyses}

We performed several sensitivity analyses. Because estimated out-of-pocket costs may not resonate with beneficiaries, we estimated willingness to pay with premiums alone; the results were qualitatively similar. Because willingness to pay may differ for disabled versus aged beneficiaries, we repeated our analysis excluding beneficiaries younger than 64; the results did not substantively differ from our primary analysis. To assess whether modelling star ratings parametrically obscured features of beneficiary's preferences, we assessed willingness to pay using a categorical star rating variable; while willingness to pay for a plan at a given rating-level varied, the overall pattern was qualitatively similar. Lastly, because HMOs tend to have higher star ratings but narrower provider networks that could influence willingness to pay relative to other coveragetypes, we estimated willingness to pay for the HMO subset by interacting cost and quality variables with $\mathrm{HMO}$ versus other coverage-types; the results were similar to our primary analysis (Appendix).

\section{DISCUSSION}

We found Medicare Advantage enrollment decisions to be informed by tradeoffs between cost and quality and local market dynamics. Our model explains nearly one-fifth of the overall variation in choices. Sponsoring organization, or brand, market 


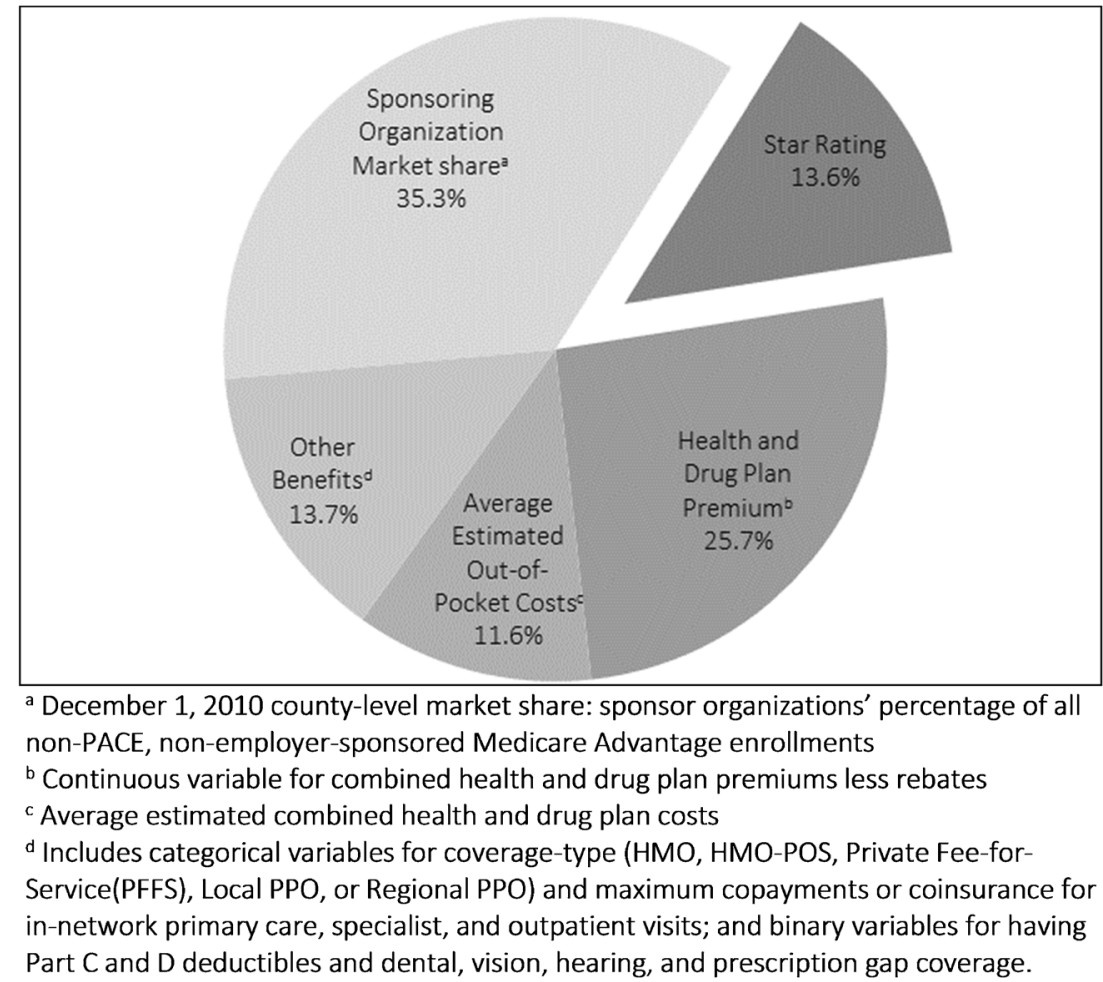

Figure 1. Proportion of explained variation in first-time medicare advantage enrollees' enrollments attributable to plan attributes.

share accounts for the largest portion of the variation, and out-ofpocket costs and premiums together explained nearly three times the variation of star ratings. Beneficiaries were willing to pay more for a higher-rated plan, but increases in willingness to pay grew less steep at higher ratings and varied among subgroups.

Our findings represent cross-sectional associations, not causal relationships; we cannot know whether unobserved factors correlated with plan attributes were responsible for choices. Market share's considerable contribution could reflect Medicare Advantage market consolidation or preferences for unmeasured attributes correlated with market share: trusted brands, word-of-mouth, or provider networks. ${ }^{1,5,8,23-25}$ Quality, favorable provider networks, and choices are likely related; access to broad networks and preferred providers has been shown to influence plan choices. ${ }^{5,726}$ Market share and quality could also be interrelated, as larger contracts tend to have higher star ratings. ${ }^{27}$

Concordant with prior research, we observed associations between enrollment and plan cost and quality. Our model explains $18.7 \%$ of the variation in plan choice, in line with other large observational studies, and suggests that while observable factors contribute to choices, much of what underlies individual preferences cannot be captured (e.g., provider networks, patient-provider relationships, health status, prior insurance experience, and market idiosyncrasies). Ultimately, in an efficient marketplace, price and quality would be more principal drivers of consumer choices than brand market power.

The diminishing marginal utility for quality among beneficiaries choosing Medicare Advantage plans may reflect the narrower range of options and preponderance of $\mathrm{HMO}$ plans at the highest ratings compared to mid-level ratings; as such, the best-rated plan may not always represent the best or most appealing choice for all beneficiaries. Alternatively, it may represent a stronger preference against the lowest-rated rather than for the highest-rated plans. This pattern may support subsequent CMS policies providing year-long open

Table 3. Beneficiaries' Estimated Willingness to Pay and Marginal Willingness to Pay in Annual Combined Health and Drug Plan Premiums and Out-of-Pocket Costs for Star Ratings

\begin{tabular}{|c|c|c|}
\hline \multirow[t]{2}{*}{ Star rating } & \multirow{2}{*}{$\begin{array}{l}\text { Willingness } \\
\text { to pay } \\
\text { Mean }\end{array}$} & \multirow{2}{*}{$\begin{array}{l}\begin{array}{l}\text { Marginal } \\
\text { willingness } \\
\text { to pay }\end{array} \\
\text { Mean }(95 \% \mathrm{CI})\end{array}$} \\
\hline & & \\
\hline Unrated plan & $\$ 4,503.34$ & \\
\hline From unrated to 2.5 -star plan & & $\begin{array}{l}-\$ 348.41 \\
(-\$ 358.51,-\$ 338.31)\end{array}$ \\
\hline 2.5 -star plan & $\$ 4,154.93$ & \\
\hline From 2.5-star to 3-star plan & & $\begin{array}{l}\$ 549.27 \\
(\$ 541.10, \$ 557.44)\end{array}$ \\
\hline 3-star plan & $\$ 4,704.19$ & \\
\hline From 3-star to 3.5-star plan & & $\begin{array}{l}\$ 429.01 \\
(\$ 423.89, \$ 434.13)\end{array}$ \\
\hline $\begin{array}{l}\text { 3.5-star plan } \\
\text { From 3.5-star to 4-star plan }\end{array}$ & $\$ 5,132.20$ & $\$ 308.75$ \\
\hline 4-star plan & $\$ 5,441.95$ & \\
\hline From 4-star to 4. 5-star plan & & $\begin{array}{l}\$ 188.49 \\
(\$ 184.51, \$ 192.46)\end{array}$ \\
\hline $\begin{array}{l}\text { 4.5-star plan } \\
\text { From } 4.5 \text {-star to } 5 \text {-star plan }\end{array}$ & $\$ 5,630.43$ & $\begin{array}{l}\$ 68.22 \\
(\$ 61.44 \quad \$ 75.01)\end{array}$ \\
\hline 5-star plan & $\$ 5,698.66$ & \\
\hline
\end{tabular}




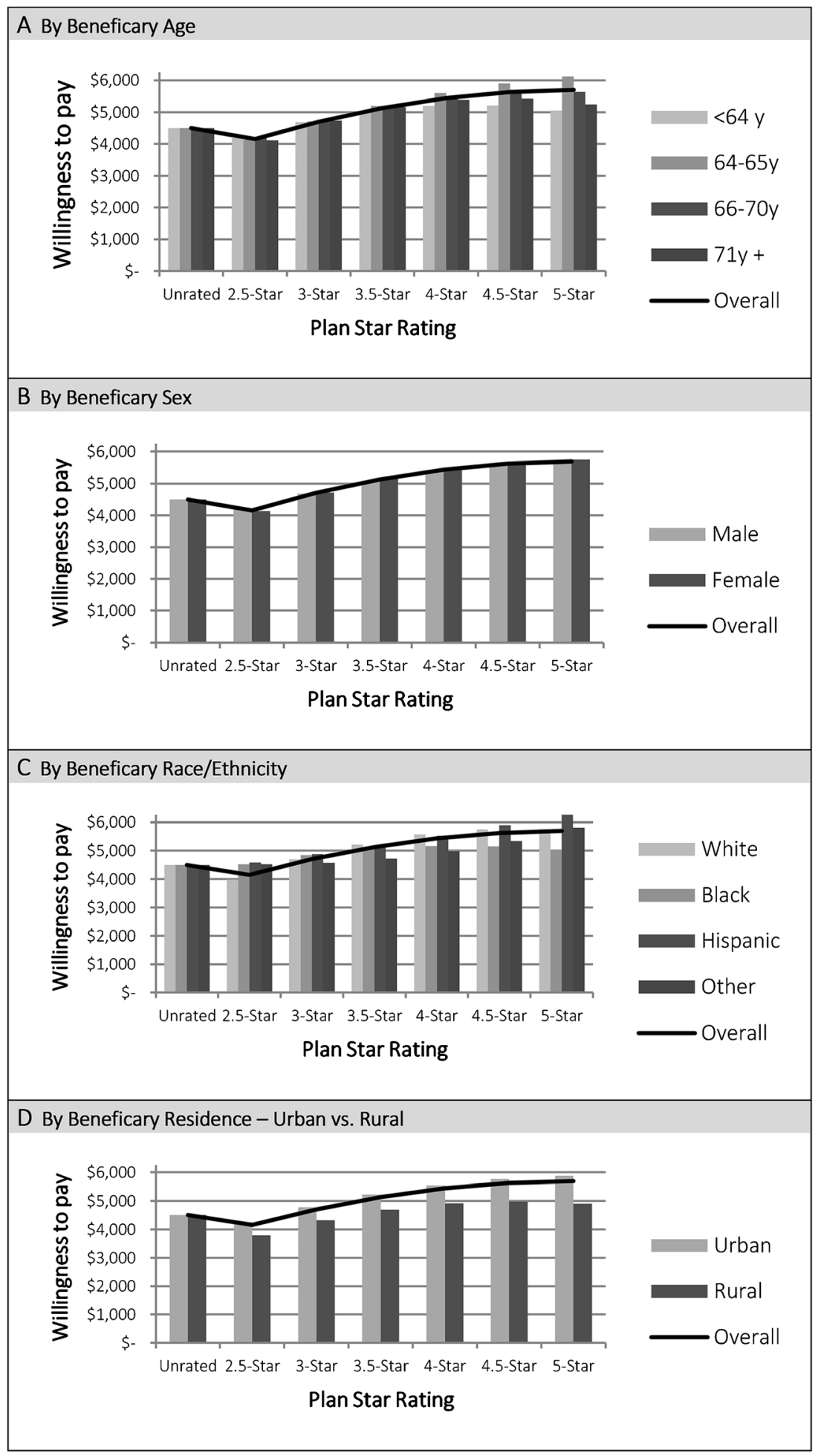

Figure 2. Beneficiary willingness to pay in annual combined health and drug plan premiums and out-of-pocket costs for star ratings, by subgroup.

enrollment for 5-star plans and bonuses to highly-rated plans, if the resulting more generous benefits and greater opportunity to enroll attracts more beneficiaries to highly rated plans.

Lesser willingness to pay among rural and black beneficiaries could signify lesser awareness of star ratings or uncaptured priorities (i.e., geographically convenient or historically trusted providers in networks, respectively). Differences in willingness to pay for quality among minorities relative to white beneficiaries (greater for Hispanic beneficiaries and lesser for black beneficiaries) could reflect targeted marketing or historical enrollment patterns, given the disproportionate minority enrollment observed in some plans. ${ }^{28}$ Greater 
willingness to pay for quality among beneficiaries aged 64 65 years, who represent the first of the baby boomers aging into Medicare, could relate to greater internet use and insurance buying experience among this group. ${ }^{29}$

\section{Policy Implications}

Our findings suggest that opportunities exist to improve how Medicare Advantage choices are informed. Relying on alternative sources of plan information, beneficiaries report low awareness and use of the star ratings and Plan Finder website., While the Plan Finder communicates high-level information about plan costs, benefits, and quality with options for more detail, in accord with expert recommendations, ${ }^{30-32}$ improvements are still needed. Given that many beneficiaries seeking plans face limitations in cognition, health literacy, internet access, and insurance purchasing experience, informing complex cost and quality comparisons between the many available plans is challenging. ${ }^{10,12,33}$ Efforts to increase awareness about the star ratings and the Plan Finder, to improve the Plan Finder's user-friendliness (e.g., simple language, streamlined tools to filter options based on personal criteria), and to augment access to in-person decision-support may help. ${ }^{5}$

Ongoing improvement of the relevance and transparency of quality information provided is warranted. ${ }^{5}$ Market share's association with enrollment underscores the importance of peer opinions; accordingly, CMS might consider including consumer reviews conveying key facets of quality. Conversely, market share's contribution suggests a role for mechanisms to engage beneficiaries to revisit prior selections, especially those for whom a less costly or higher quality alternative exists. CMS's letters to beneficiaries enrolled in persistently low-rated plans is an initial step, but more may be necessary. ${ }^{3,34}$ Better understanding of which dimensions of quality are most important to beneficiaries, which specific measures are most meaningful to beneficiaries, and which means of communication of quality information are most effective for reaching and supporting beneficiaries is needed.

If making the highest-quality plans more attractive for enrollment is the goal, the diminishing marginal utility for quality at higher star ratings and disparities in willingness to pay may argue for more education about high-quality plans. While the highest-rated plan may not always be the best-fit or highest-value option for a given beneficiary, differential willingness to pay for quality among key subgroups argues for targeted outreach and education. Moreover, by excluding beneficiaries eligible for the low-income subsidy, our analyses omit a population of beneficiaries for whom health literacy is likely more limited and for whom efforts at outreach and education to foster selection of high-quality and high-value plans may be most critical.

\section{Limitations}

Our study has limitations. Exclusion of beneficiaries choosing Special Needs, PACE, cost, employer-sponsored plans, or plans without prescription coverage limits generalizability to those to whom these appeal. Our focus on first-time Medicare Advantage enrollees eliminates prior enrollments' potential influence, but limits generalizability to extant enrollees and precludes accounting for health status and utilization, which could influence preferences. Quality ratings are not assessed for traditional Medicare and our analysis cannot address the choice between traditional Medicare and Medicare Advantage. Income likely influences willingness to pay; however, beneficiary-level income data were unavailable and local averages would not primarily reflect Medicare beneficiaries; exclusion of beneficiaries deemed eligible for the low-income subsidy ameliorates this shortcoming somewhat, excluding those for whom higher-costs are likely more deterring. Finally, we cannot account for several factors that may influence choices or willingness to pay (i.e., provider networks, health status, income, health literacy); these warrant assessment in future work.

\section{CONCLUSIONS}

While Medicare Advantage plan's costs and quality influence enrollment preferences, brand market share also contributes heavily to beneficiaries' choices. As CMS strives to promote informed decisions in the Medicare Advantage marketplace, opportunities exist to refine the use and understanding of plan information by Medicare beneficiaries. Ensuring access to clear and compelling cost and quality data to inform decisions in the Medicare Advantage marketplace and other insurance exchanges will be important to the long-term success of these market-based systems.

Acknowledgements: This study was approved as exempt by the Institutional Review Boards of Partners Healthcare and CUNY Hunter College.

The views expressed in this manuscript represent the authors and do not necessarily represent the views of the Centers for Medicare and Medicaid Services, the Department of Health and Human Services, or the U.S. Government.

Drs. Reid and Deb had full access to all of the data in the study and take responsibility for the integrity of the data and the accuracy of the data analysis.

No outside funding sources contributed to this research.

Portions of this work were presented in oral presentations at the Society of General Internal Medicine Annual Meeting in San Diego, CA on 26 April 2014 and the AcademyHealth Annual Research Meeting in San Diego, CA on 8 June 2014.

Conflict of interest: All authors were employees or affiliates of the Centers for Medicare and Medicaid Services for some portion of the time during which this study was conducted.

Dr. Shrank reports previously receiving consulting fees from United Healthcare and grant support from CVS Caremark, Aetna, and the National Association of Chain Drug Stores. Dr. Shrank and Dr. Howell have both since taken employment at CVS Caremark.

The authors declare that they have no further conflicts of interest to disclose.

Corresponding Author: Rachel O. Reid, MD, MS; Department of MedicineBrigham Women's Hospital, Boston, MA, USA (e-mail: rreid3@partners.org). 


\section{REFERENCES}

1. Gold M, Jacobson G, Damico A, Neuman T. Medicare Advantage 2013 Spotlight: Enrollment Market Update. 2013; http://kff.org/medicare/ issue-brief/medicare-advantage-2013-spotlight-enrollment-market-update/. Accessed June 12, 2015.

2. Jacobson GA, Neuman P, Damico A. At least half of new medicare advantage enrollees had switched from traditional medicare during 200611. Health Aff. 2015;34(1):48-55.

3. Centers for Medicare \& Medicaid Services. Medicare Plan Finder for Health, Prescription Drug, and Medigap Plans. https://www.medicare.gov/find-aplan/questions/home.aspx. Accessed June 12, 2015.

4. Medicare Payment Advisory Commission. Report to Congress: Medicare Payment Policy; Online Appendix 12-A: The Medicare Advantage Program Status Report, Measures Composing the Star System. http://www. medpac.gov/documents/reports/mar11_ch12_appendix.pdf. Accessed June 12, 2015.

5. Jacobson G, Swoope C, Perry M, Slosar MC. How are Seniors Choosing and Changing Health Insurance Plans? 2014; http://kff.org/report-section/how-are-seniors-choosing-and-changing-health-insurance-planswhat-factors-lead-beneficiaries-to-not-be-enrolled-in-the-lowest-costhealth-plan/. Accessed June 12, 2015

6. Harris Interactive. Medicare Star Quality Rating System Study: Key Findings. https://kaiserhealthnews.files.wordpress.com/2012/05/ 101011 medicarerankingsharrissurveyinfo.pdf. Accessed June 12, 2015.

7. Kolstad JT, Chernew ME. Quality and consumer decision making in the market for health insurance and health care services. Med Care Res Rev. 2009;66(1 suppl):28S-52S.

8. Dafny L, Dranove D. Do report cards tell consumers anything they don't already know? The case of medicare HMOs. Natl Bur Econ Res Work Pap Ser. 2008;39(3):790-821.

9. Tu TH, Lauer JR. Word of mouth and physician referrals still drive health care provider choice. 2008; http://www.hschange.com/CONTENT/1028/ 1028.pdf. Accessed June 12, 2015.

10. McWilliams JM, Afendulis CC, McGuire TG, Landon BE. Complex Medicare advantage choices may overwhelm seniors-especially those with impaired decision making. Health Aff (Project Hope). 2011;30(9):17861794.

11. Kuye IO, Frank RG, McWilliams JM. Cognition and take-up of subsidized drug benefits by medicare beneficiaries take-up of drug benefits by medicare beneficiaries. JAMA Int Med. 2013;1-8.

12. Chan S, Elbel B. Low cognitive ability and poor skill with numbers may prevent many from enrolling in Medicare supplemental coverage. Health Aff. 2012;31(8): 1847-1854

13. Hanoch Y, Wood S, Barnes A, Liu PJ, Rice T. Choosing the right medicare prescription drug plan: the effect of age, strategy selection, and choice set size. Health Psychol Off J Div Health Psychol Am Psychol Assoc. 2011;30(6):719-727.

14. Wood S, Hanoch Y, Barnes A, et al. Numeracy and Medicare Part D: the importance of choice and literacy for numbers in optimizing decision making for Medicare's prescription drug program. Psychol Aging. 2011;26(2):295-307.

15. Bundorf MK, Szrek H. Choice set size and decision making: the case of Medicare Part D prescription drug plans. Medical Decis Making Int J Soc Med Decis Making. 2010;30(5):582-593.
16. Scanlon DP, Chernew M, Lave JR. Consumer health plan choice: current knowledge and future directions. Annu Rev Public Health. 1997;18:507-528.

17. Reid RO, Deb P, Howell BL, Shrank WH. Association between medicare advantage plan star ratings and enrollment. JAMA. 2013;309(3):267-274.

18. Centers for Medicare \& Medicaid Services. CMS Integrated Data Repository (IDR). https://www.cms.gov/Research-Statistics-Data-and-Systems/ Computer-Data-and-Systems/IDR/index.html?redirect=/IDR/. Accessed June 12, 2015.

19. Centers for Medicare \& Medicaid Services. Details for System of Records: 09-70-0500 Health Plan Management System (HPMS). https://www.cms. gov/Regulations-and-Guidance/Guidance/PrivacyActSystemofRecords / Systems-of-Records-Items/CMS044932.html. Accessed June 12, 2015.

20. Centers for Medicare \& Medicaid Services. Part D Performance Data http://www.cms.gov/Medicare/Prescription-Drug-Coverage/PrescriptionDrugCovGenIn/PerformanceData.html. Accessed June 12, 2015.

21. Eicheldinger C, Bonito A. More accurate racial and ethnic codes for Medicare administrative data. Health Care Financing Rev. 2008;29(3):27-42.

22. Atherly A, Dowd BE, Feldman R. The effect of benefits, premiums, and health risk on health plan choice in the Medicare program. Health Serv Res. 2004;39(4 Pt 1):847-864.

23. Edgman-Levitan S, Cleary PD. What information do consumers want and need? Health Aff. 1996;15(4):42-56.

24. Sorensen AT. Social learning and health plan choice. RAND J Econ. 2006;37(4):1-29.

25. Mechanic D. Consumer choice among health insurance options. Health Aff. 1989;8(1): 138-148.

26. Harris KM. Can high quality overcome consumer resistance to restricted provider access? Evidence from a health plan choice experiment. Health Serv Res. 2002;37(3):551-571.

27. Xu P, Burgess JJF, Cabral H, Soria-Saucedo R, Kazis LE. Relationships between medicare advantage contract characteristics and quality-of-care ratings an observational analysis of medicare advantage star ratings contract characteristics and the delivery of quality of care. Ann Intern Med. 2015;162(5):353-358.

28. Weinick R, Haviland A, Hambarsoomian K, Elliott MN. Does the racial/ ethnic composition of medicare advantage plans reflect their areas of operation? Health Serv Res. 2014;49(2):526-545.

29. Zickuhr K. Generations 2010. 2010; http://www.pewinternet.org/ / media//Files/Reports/2010/PIP_Generations_and_Tech10.pdf. Accessed June 12,2015

30. Hibbard J, Sofaer S. http://archive.ahrq.gov/professionals/quality-patient-safety/quality-resources/tools/pubrptguide 1/pubrptguide1.pdf. Agency for Healthcare Research and Quality 2010; http://www.ahrq.gov/ legacy/qual/pubrptguidel.htm. Accessed June 12, 2015.

31. Hibbard JH, Stockard J, Tusler M. Does Publicizing Hospital Performance Stimulate Quality Improvement Efforts? Health Aff. 2003;22(2):84-94.

32. Mehrotra A, Hussey PS, Milstein A, Hibbard JH. Consumers' and providers' responses to public cost reports, and how to raise the likelihood of achieving desired results. Health Aff. 2012;31(4):843-851.

33. Gold M. Medicare Advantage-lessons for Medicare's future. N Engl J Med. 2012;366(13): 1174-1177.

34. Jaffe S. Medicare Trying To Nudge Seniors Out Of Plans with Low Ratings. http://www.kaiserhealthnews.org/stories/2012/november/06/medicarestar-rating-notices.aspx. Accessed June 12, 2015. 